\title{
Spectral Decomposition Using the CEEMD Method: a Case Study from the Carpathian Foredeep
}

\author{
Anna KWIETNIAK, Kamil CICHOSTĘPSKI, and Monika KASPERSKA
}

AGH University of Science and Technology, Faculty of Geology, Geophysics and Environmental Protection, Kraków e-mails: ania.kwietniak@gmail.com (corresponding author), krol@agh.edu.pl,kcichy@agh.edu.pl

\begin{abstract}
The purpose of this work is to select the optimal spectral decomposition (SD) method for channel detection in the Miocene strata of the Carpathian Fordeep, SE Poland. For analysis, two spectral decomposition algorithms were tested on 3D seismic data: the first, based on Fast Fourier Transform (FFT), and second, on Complete Ensemble Empirical Mode Decomposition (CEEMD). Additionally the results of instantaneous frequency (IF) were compared with the results of peak frequency (PF) computed after the CEEMD. Both algorithms of SD enabled us to interpret channels, but the results are marginally different, i.e. the FFT shows more coarse, linear structures, that are desirable for channel interpretation, whereas the CEEMD does not highlight these structures as clearly and shows more, what the authors believe to be, noise.
\end{abstract}

Key words: spectral decomposition, empirical mode decomposition, frequency analysis, channels.

\section{INTRODUCTION}

Information on how the frequency content of a signal varies with time is a useful tool for seismic interpretation. Hence, the time-frequency analysis is a method widely used in seismic processing and interpretation (Chopra and 
Marfurt 2007). The decomposition methodologies are various and diverse and are suited for particular targets, i.e. each method has its own advantages and disadvantages and different applications requiring different methods (Castagna 2006). The aim of this research is to compare two algorithms of spectral decomposition for channel detection in the Carpathian Foredeep.

The analysis was carried out using the 3D seismic survey of the Trzciana-Cierpisz-Zaczernie region. Additionally, instantaneous seismic attributes were used and their results have been compared with the results of spectral decomposition. Channel detection was performed mostly on horizontal slices. Spectral decomposition was used to detect channels that are embedded in the Miocene sediments. The first algorithm that was used was based on a short window discrete (fast) Fourier transform. The choice of this method was inspired by the classical paper of Partyka (Partyka et al. 1999). These results are well-known among seismic interpreters and spectral decomposition based on the FFT is considered as the first widely available method of SD.

Nowadays there are numerous algorithms used in the analysis of spectral decomposition. Decomposition based on continuous wavelet transform holds a good resolution for events of various lengths since it is related to the central frequency of the used wavelet. Decomposition based on the maximum entropy method, which is based on the $\mathrm{Z}$ transform, has a remarkable ability to zoom in on extremely narrow features (Masters 1995). Decomposition based on Wigner-Ville distribution depends on careful choice of the parameters used, but once properly set it produces high-resolution time-frequency representations ( $\mathrm{Li}$ and Zheng 2008).

From among the many decomposition algorithms available, the complete ensemble empirical mode decomposition was chosen for the comparison with the FFT method. The reason for this choice was that it is a relatively new algorithm, and until now it has not been widely available in computational packages. Its computation is quite complex, so the results could possibly be accurate. Finally, the authors were inspired by the recently published paper (Han and Van der Baan 2013), which suggests that it has advantages over others methods.

\section{GEOLOGICAL SETTING OF THE AREA}

The study area (Fig.1) is located in the Carpathian Foreland Basin which was formed during the Eggenburgian period (Kotlarczyk 1985) or the Egarian (Oszczypko-Clowes et al. 2012), it is, to the front of an accretionary prism that had thrusted northwards onto the platform basement. The thickness of the Miocene strata changes from $7 \mathrm{~km}$ in the south, through an average of $2.5 \mathrm{~km}$ in the centre, to zero along the northern margin (Oszczypko 1996). 


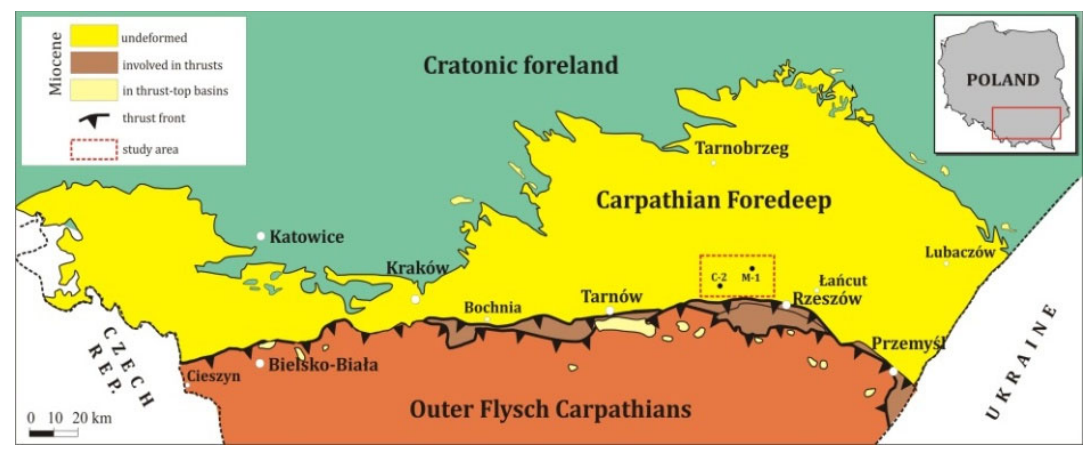

Fig. 1. Location of the study area in comparison to other major geological units (courtesy of Porębski, Porębski 2014, unpublished). C-2 and M-1: wells used for analysis.

The Trzciana-Cierpisz-Zaczernie 3D seismic survey is situated approximately $4 \mathrm{~km}$ north from the frontal thrust edge, in the SE part of the basin, that is similarly characterised by a NW-trending basement elevation referred to as the Cierpisz and Mrowla-Bratkowice heights. These heights are separated by troughs of some significant depth: Kielnarowa, Kolbuszowa and Świlcza valleys (Fig. 2).

The through-valley system most likely belongs to a dominating erosional valley system which developed along the entire outer Carpathians (Karnkowski and Ozimowski 2001) and which seems to merge with the older flexural unconformity in the Carpathian Basin. The high-relief morphology of the basement was very probably the main factor that controlled the location of compaction-driven traps in the Miocene overburden. The channels occur within the Miocene succession which consists mainly of sandstones and mudstones of the Badenian and Pannonian age. The Miocene strata (Fig. 3) is represented here by sediments of significant thickness: it reaches up to 2950 meters, $1000 \mathrm{~m}$ of which are enclosed in the south within the valley confinement (basement). In the study area the Miocene succession was divided into three main basin-fill packages basing on seismic and well data: (A) ponded basin-plain fines interbedded with distal, heterolithic submarine fans, (B) subaqueous fronts of sandy to heterolithic deltas, and (C) muddy, delta-fed slopes recorded in seismic sections by basinward accreting clinoforms (Fig. 3) (Porębski et al. 2014). A transition zone between packages B and A reveals some well-developed, seismic-scale channel forms, which are clustered within an interval of 1050-1400 ms (TWT) and appear to be largely encased within fine-grained sediments (Krawiec et al. 2008) belonging to the slope-prodelta facies association. The channels show a straight to gentle sinuous geometry, a NE-SW direction and tending to widen northeastwards. 


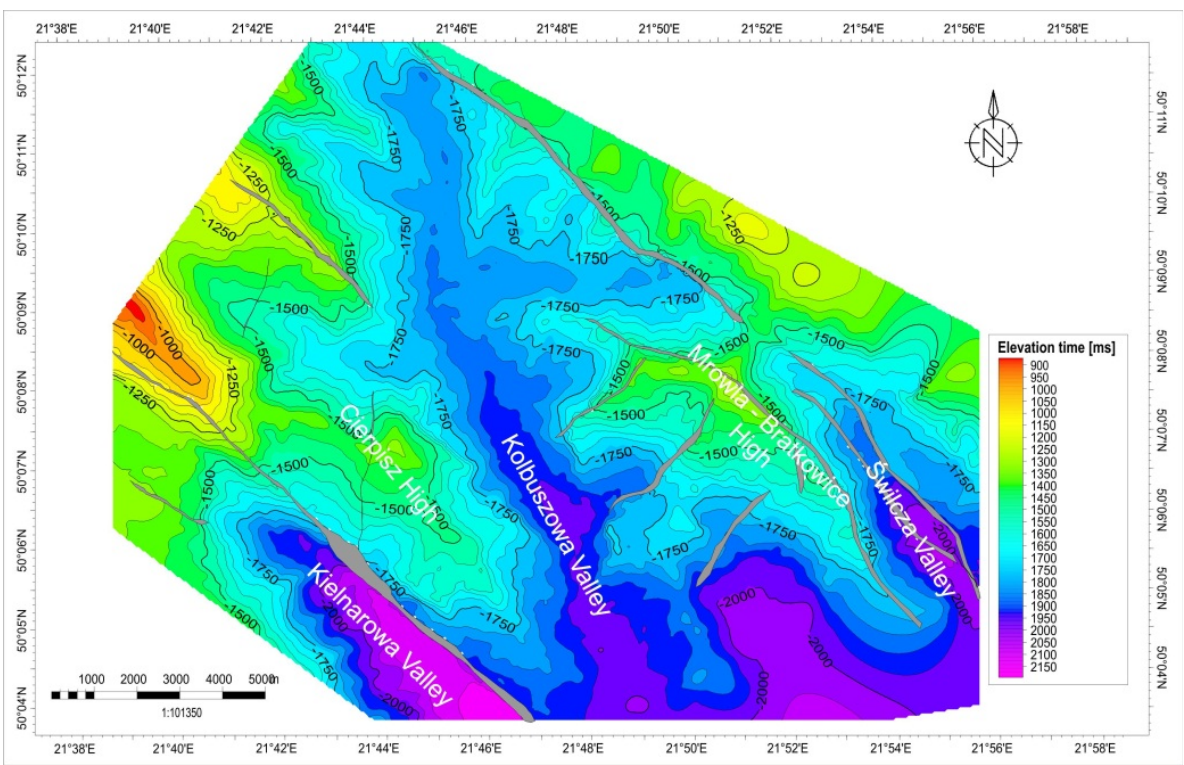

Fig. 2. Elevation of the base-of-Miocene unconformity with valleys and highs.

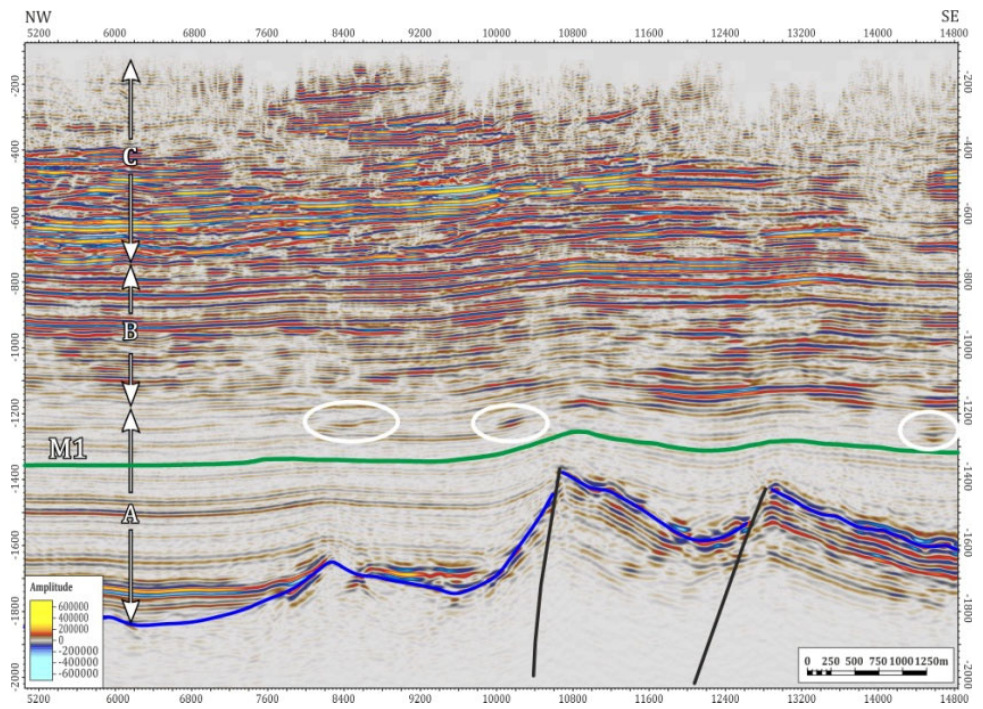

Fig. 3. Seismic profile (crossline 566) with marked sedimentary packages (A, B, C) and channels (ellipses). Navy blue boundary - base-of-Miocene unconformity.

The presence of high-amplitude channel reflections suggests that they may be at least partly sandy in nature (e.g., Damuth et al. 1983). In Fig. 3, except for sedimentary packages, channels are also visible (marked by white 
ellipses). The goal of the applied methodology was to enhance their seismic signature.

\section{METHODS}

Two spectral decomposition algorithms were used for analysis. The spectral decomposition based on the FFT algorithm is considered historically to have been the first spectral decomposition method. It is widely developed and despite its simplicity it usually yields valuable results. The process of computation is considered rather straightforward and requires just two basic parameters: the length of the time window expressed in milliseconds, determining the output resolution, and the step, given in Hertz. The amplitude spectrum is calculated for a given frequency. Ideally, the time-window is proportional to one seismic event (horizon). The benefit of the FFT method is that it works well when the interpreted horizon is clearly defined and the interpretation focuses on local changes of amplitude. For such a separate event, decomposition parameters can be individually designed; however, when the aim is to interpret the seismic volume as a whole, its results may be misleading. Hence, the time-window must be carefully chosen and it is considered as the most important factor for spectral decomposition via the use of the FFT method (Partyka et al. 1999). The optimal way to maintain the proper trade-off between temporal and spectral resolution, varying timewindow-length is to incorporate available geophysical data, such as well log data. In interpretation, two wells (C-2 and M-1, Fig. 1) were used to find the optimal length of the time-window. Gamma ray changes enabled the verification of possible channels. An ideal facial analysis was developed based on the gamma ray log, proposing several window lengths for the decomposition process. Tests included windows of lengths: $25,30,35,40,45$ and 50 milliseconds. Finally, the time-window was set to $40 \mathrm{~ms}$.

The second decomposition algorithm was based on the complete ensemble empirical mode decomposition (CEEMD). The advantages of this algorithm are described by Han and Van der Baan (2013), and Huang and Wu (2008). The results herein presented suggest almost unconditional superiority of the CEEMD algorithm in comparison with the FFT. However, we found it difficult to compare the results of the CEEMD and FFT presented in Figure 19 on page O18 in Han and van der Baan (2013) due to the inconsistent colour scale.

The following assumption characterizes the CEEMD algorithm: at any given time, the data may have many coexisting simple oscillatory modes of significantly different frequencies, one superimposed upon the other (Huang and $\mathrm{Wu}$ 2008). These modes are called intrinsic mode functions (IMFs). The scope of the CEEMD allows the unravelling of seismic traces into the finite 
set of IMFs, each of which may correspond to the exact frequency. The algorithm implemented enables an additional computation of the peak frequency - which is the frequency where the maximum spectral amplitude is localized. This can be comparable with instantaneous frequency. Instantaneous frequency is the frequency where the central mass of the spectrum cumulates (Taner et al. 1979).

For analysis, two instantaneous seismic attributes were incorporated: phase and frequency. Instantaneous frequency was used in order to verify the results of the spectral decomposition of the CEEMD algorithm (peak frequency after the decomposition process). The instantaneous phase was incorporated to study the local wavelet stability; it proved to be stable for the majority of the 3D seismic volumes.

The main aim of this work is to determine which algorithm of decomposition gives better results in the study area. In particular, we wanted to answer the question whether the CEEMD algorithm has significant advantages (Han and Van der Baan 2013) over the FFT algorithm. The steps of our analysis were as follows:

a Decomposition based on the CEEMD algorithm was computed for the whole $3 \mathrm{D}$ volume. The output was derived from iso-frequency slices. We analysed the frequencies of 35, 20,50 Hz. Additionally, this algorithm enables us to compute peak frequency (PF) of the decomposed volume, which can be compared with the results of instantaneous frequency (IF).

a The FFT algorithm was applied. Based on well M-1 (gamma ray $\log$ ) we found the optimal length of the window used for spectral decomposition for the problem at hand. Then we computed SD with the window length of $40 \mathrm{~ms}$. Slices of the specific frequency were chosen basing on the same pattern as for the CEEMD decomposition.

- Instantaneous frequency was computed.

- All results were normalized in scale and compared to obtain an unified colour scale.

\section{RESULTS}

The analysis of phase stability via computing instantaneous amplitude and instantaneous phase proved that the wavelet is stable in the area being studied. Only at the edges of the 3D seismic survey the wavelet loses its consistency and phase differs from zero. However, this tilt with a maximum phase of $50^{\circ}$ does not impede the application of spectral decomposition. Such a preliminary analysis enables us to apply the chosen methodology of spectral decomposition. 

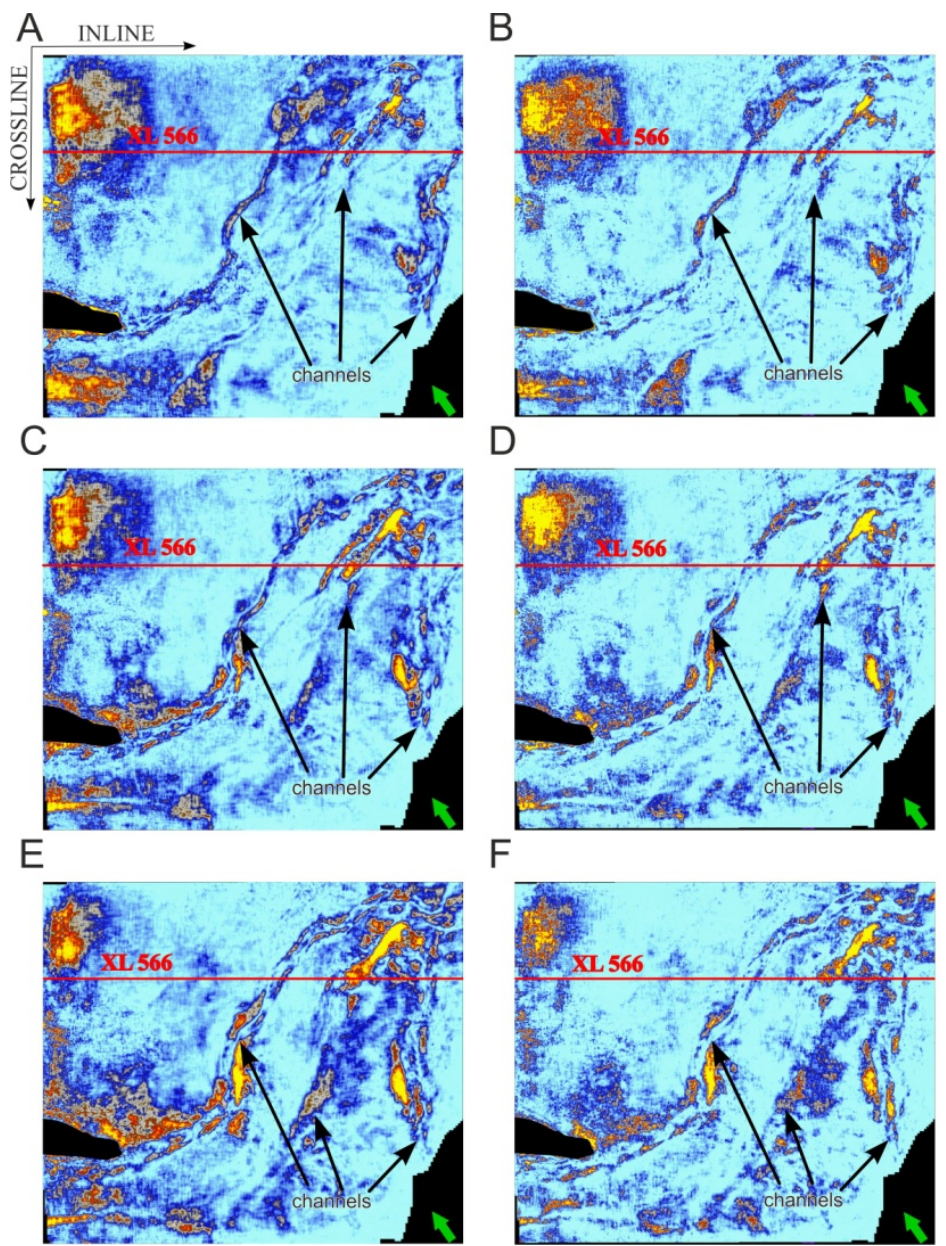

$\mathrm{F}$

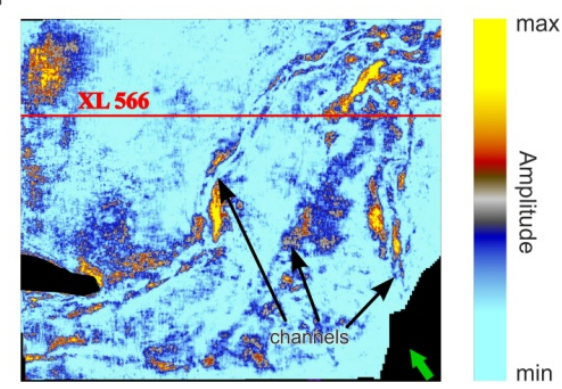

Fig. 4. Results of spectral decomposition for $35 \mathrm{~Hz}$ : (A) FFT $140 \mathrm{~ms}$ above M1 horizon, (B) CEEMD $140 \mathrm{~ms}$ above M1 horizon, (C) FFT $170 \mathrm{~ms}$ above M1 horizon, (D) CEEMD $170 \mathrm{~ms}$ above M1 horizon, (E) FFT M1 $200 \mathrm{~ms}$ above M1 horizon, and (F) CEEMD $200 \mathrm{~ms}$ above M1 horizon.

We present results on structural slices parallel to the horizon which is a bottom of the channel sequence (M1). Results are compared in the following manner: for both algorithms the same seismic features are pictured, so that the reader can simultaneously verify potential differences between the methods.

In Figs 4-6, results of spectral decomposition of the Miocene sediments are shown. Colour scale is consistent for all figures, warm colours correspond to high amplitudes and cold to decreasing amplitudes. Channels are 


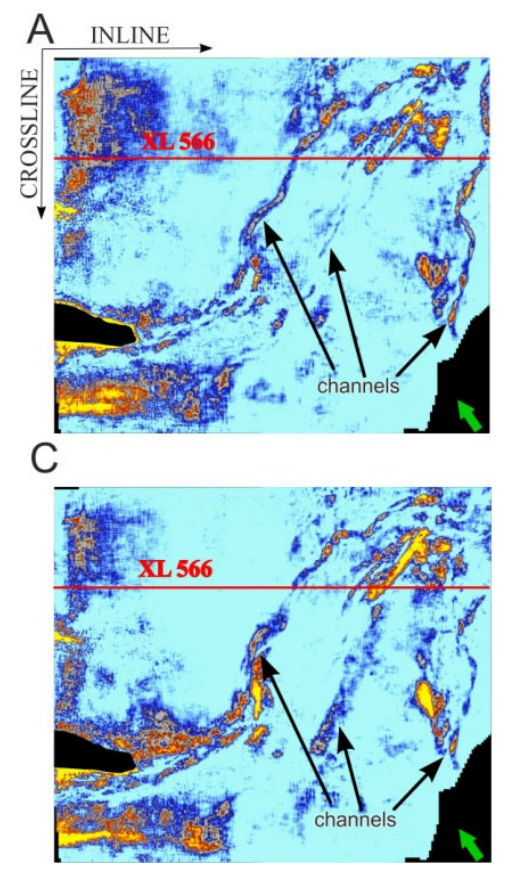

B

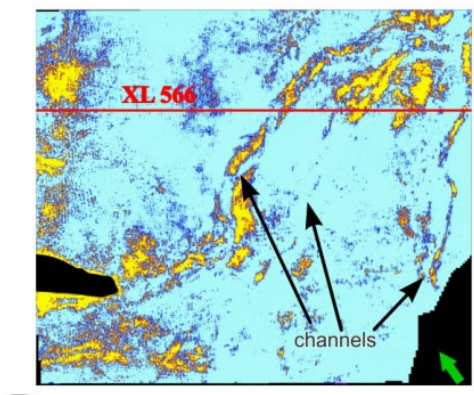

D

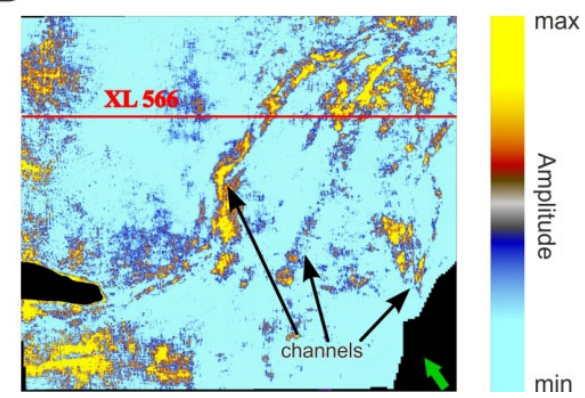

Fig 5. Results of spectral decomposition for $20 \mathrm{~Hz}$ : (A) FFT $140 \mathrm{~ms}$ above M1 horizon, (B) CEEMD $140 \mathrm{~ms}$ above M1 horizon, (C) FFT $170 \mathrm{~ms}$ above M1 horizon, and (D) CEEMD $170 \mathrm{~ms}$ above M1 horizon.

visible on the 2D seismic section (Fig. 3), but only a 3D view enables a precise analysis.

Channels are pointed out in every figure using black arrows. The general direction of the channels is E-W (green arrow in the bottom-right hand corner in all figures indicates north). Slices are shown from the deepest to the shallowest. Caption ' 140 ms above M1 horizon' (see Figs 4-8) indicates that structural slice is located $140 \mathrm{~ms}$ upwards from the M1 horizon. In the left edge of the survey area the basement reaches its most shallow part (black polygon). This should not be confused with the features related to the channels, however its existence must have had an influence on their morphology.

Channels are clearly revealed by both algorithms, particularly by the frequency of $35 \mathrm{~Hz}$ (Fig. 4). Both decomposition methods show clear channel shape and the linear-like continuity of related features.

With the use of different frequencies, the possibility of separating features of different scales is possible. The use of high frequencies enables us to depict smaller features, whereas low frequencies show more coarse structures. This effect is visible by comparing Figs 4, 5 and 6. In Fig. 6, in its central part there is a fading sign of a small channel, that was barely visible with 

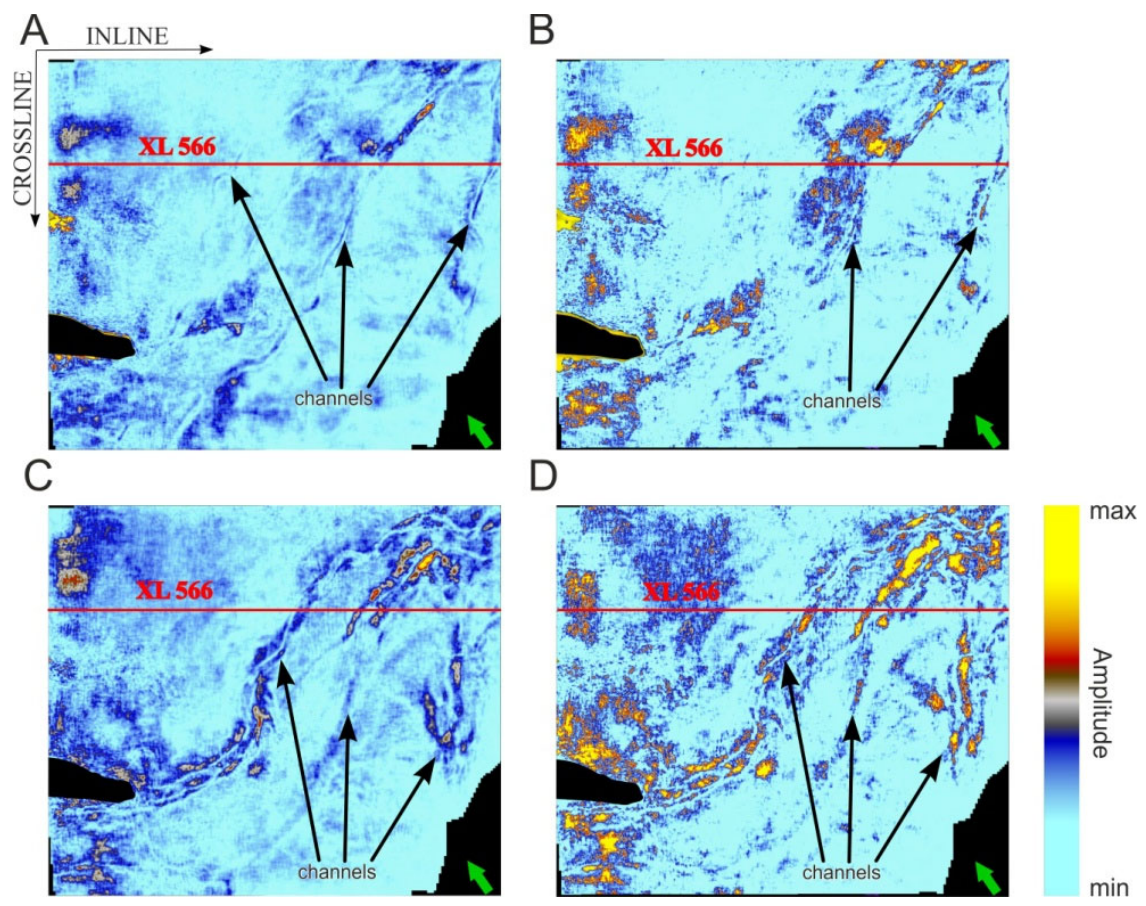

Fig. 6. Results of spectral decomposition for $50 \mathrm{~Hz}$ : (A) FFT $100 \mathrm{~ms}$ above M1 horizon, (B) CEEMD $100 \mathrm{~ms}$ above M1 horizon, (C) FFT $180 \mathrm{~ms}$ above M1 horizon, and (D) CEEMD $180 \mathrm{~ms}$ above M1 horizon.

lower frequencies (Fig. 6A, the first arrow from left). We believe that its parameters, i.e. width and thickness, are smaller than those which are visible for the lower frequencies. For this channel only the FFT method proved to be successful (Fig. 6A, C) - results of the CEEMD do not show such a small, continuous structure in the central area of the seismic survey (Fig. 6B, D).

In order to see the differences simultaneously, the procedure of corendering was performed. The result can be examined in Figs 7 and 8. Each image in these figures shows one horizontal slice being a result of overlapping the output corresponding to the separate frequencies; in this case $20 \mathrm{~Hz}$ and $45 \mathrm{~Hz}$. The amplitude scale is unified (uniformalised) indicating two extrema concurrently, with blue linked to low frequencies - here $25 \mathrm{~Hz}$ and brown to higher frequencies $-45 \mathrm{~Hz}$. Mixing outputs of a different frequency enables us to analyse results that depicted different geological features related to different geometrical scales simultaneously, i.e. higher frequencies reveal features of more detailed character, whereas lower frequencies those which are more coarse. In terms of the CEEMD method such a straightforward explanation of the resolving power of the method cannot be given. 


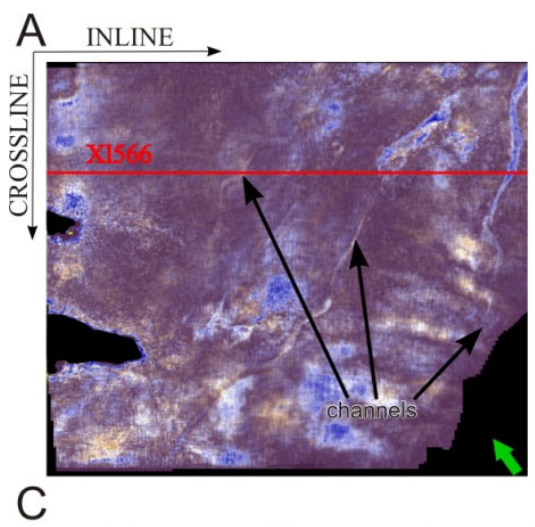

B

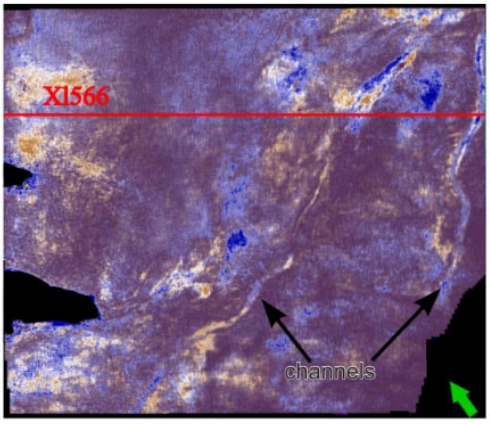

D

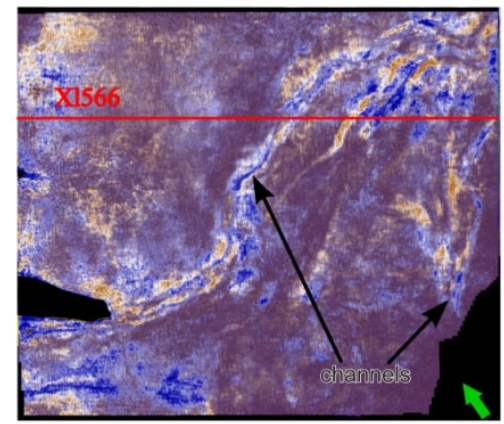

$\mathrm{E}$

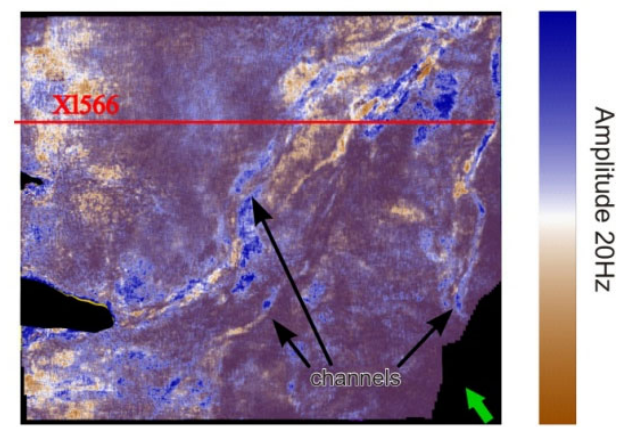

$\mathrm{F}$
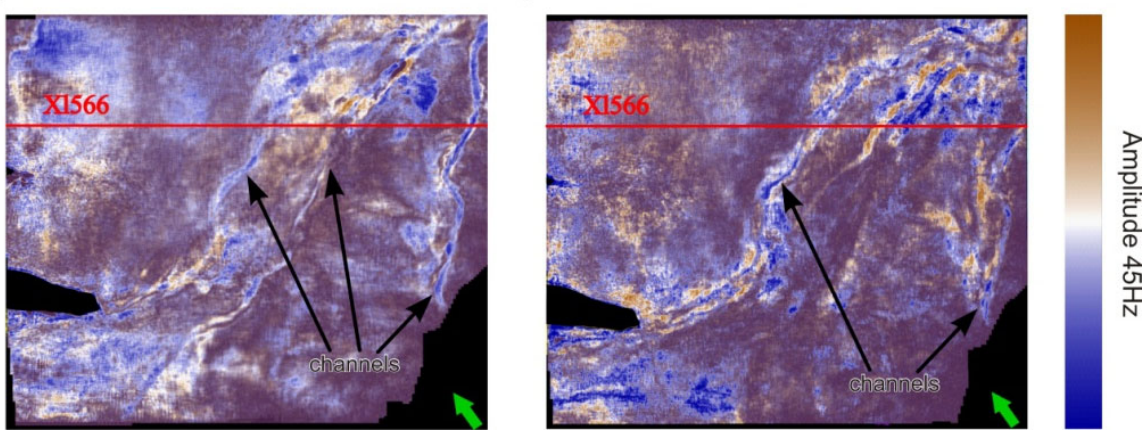

Fig. 7. Results of spectral decomposition for overlapped 20 and $45 \mathrm{~Hz}$ with different time frames: (A) FFT $60 \mathrm{~ms}$ above M1 horizon, (B) CEEMD $60 \mathrm{~ms}$ above M1 horizon, (C) FFT $90 \mathrm{~ms}$ above M1 horizon, (D) CEEMD $90 \mathrm{~ms}$ above M1 horizon, (E) FFT $120 \mathrm{~ms}$ above M1 horizon, and (F) CEEMD $120 \mathrm{~ms}$ above M1 horizon.

Overlapping the FFT results of different frequencies enables us to interpret the smaller channel (the first arrow from the left in Fig. 7A) that was spotted firstly in Fig. 6. It is visible when the shorter time window is used, so 

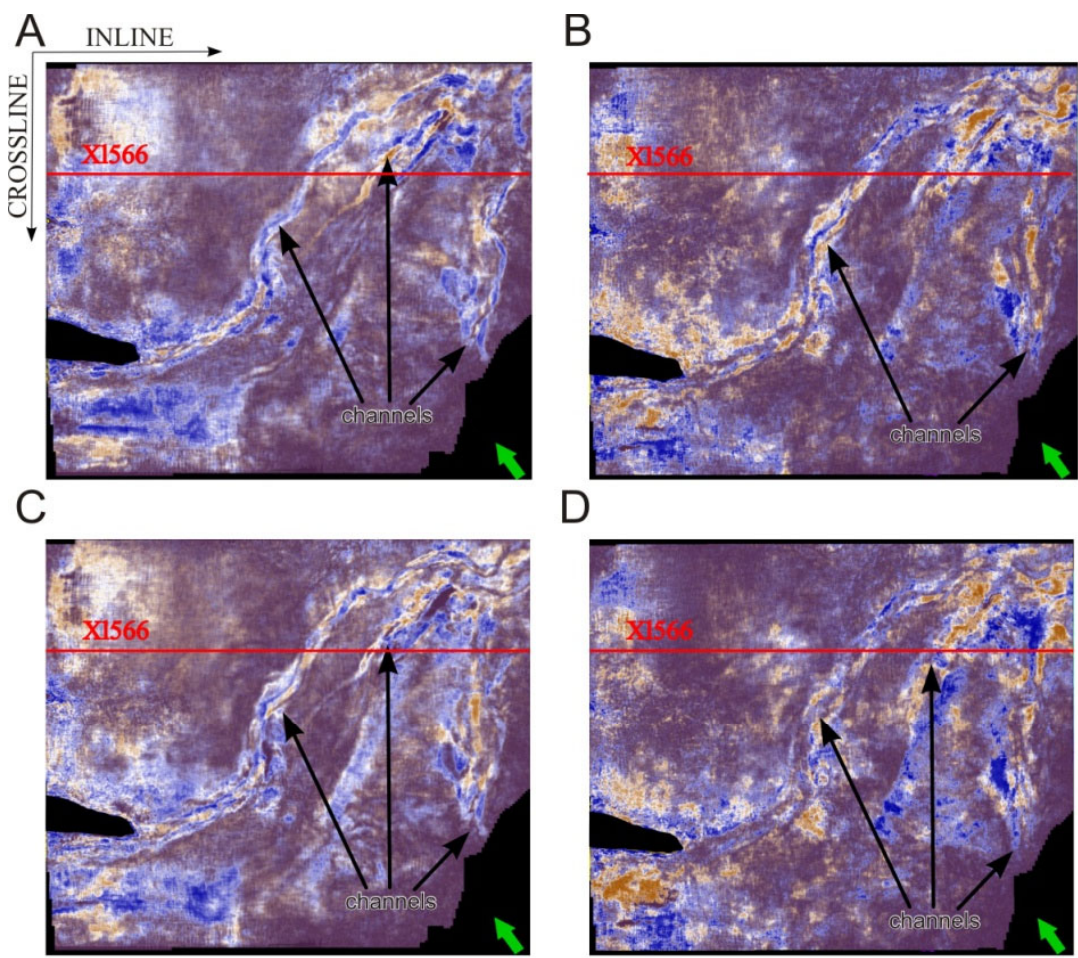

$\mathrm{E}$
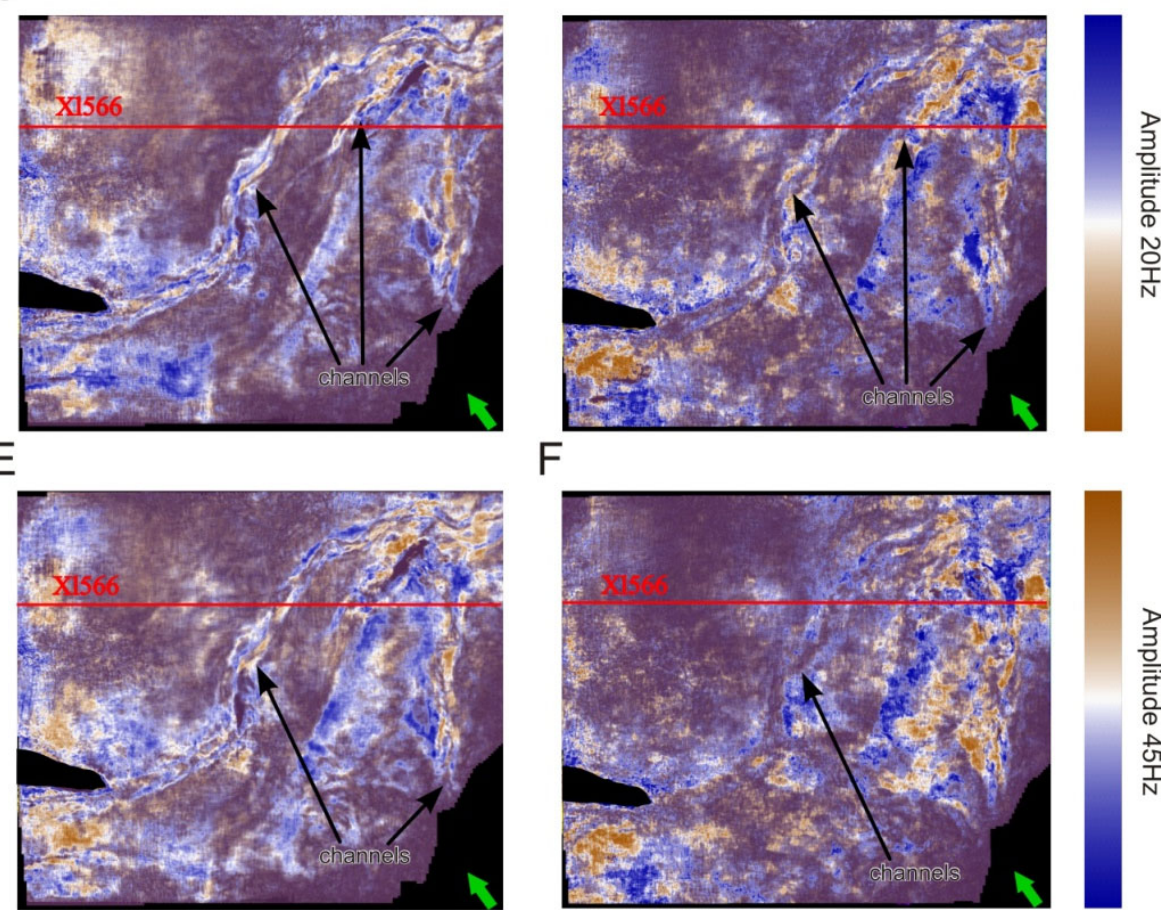

Fig. 8. Results of spectral decomposition for overlapped 20 and $45 \mathrm{~Hz}$ with different time frames: (A) FFT $150 \mathrm{~ms}$ above M1 horizon, (B) CEEMD $150 \mathrm{~ms}$ above M1 horizon, (C) FFT $180 \mathrm{~ms}$ above M1 horizon, (D) CEEMD $180 \mathrm{~ms}$ above M1 horizon, (E) FFT $210 \mathrm{~ms}$ above M1 horizon, and (F) CEEMD 210ms above M1 horizon.

we have reason to suspect that this channel represents smaller features that are embedded in the seismic data. This small channel is hardly noticeable on the CEEMD results (Fig. 7B). 


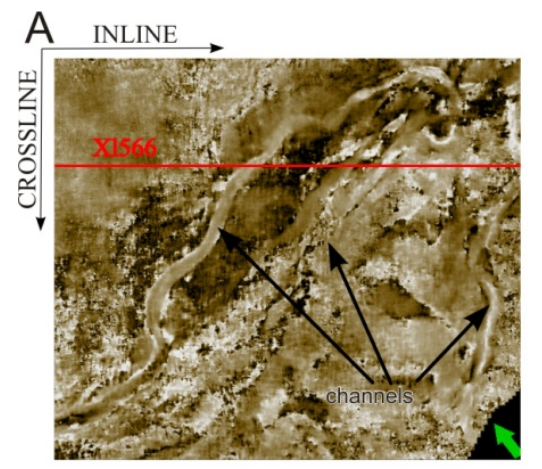

B

Fig. 9. Instantaneous frequency (A) and peak frequency (computed after CEEMD spectral decomposition) (B) $120 \mathrm{~ms}$ above M1.

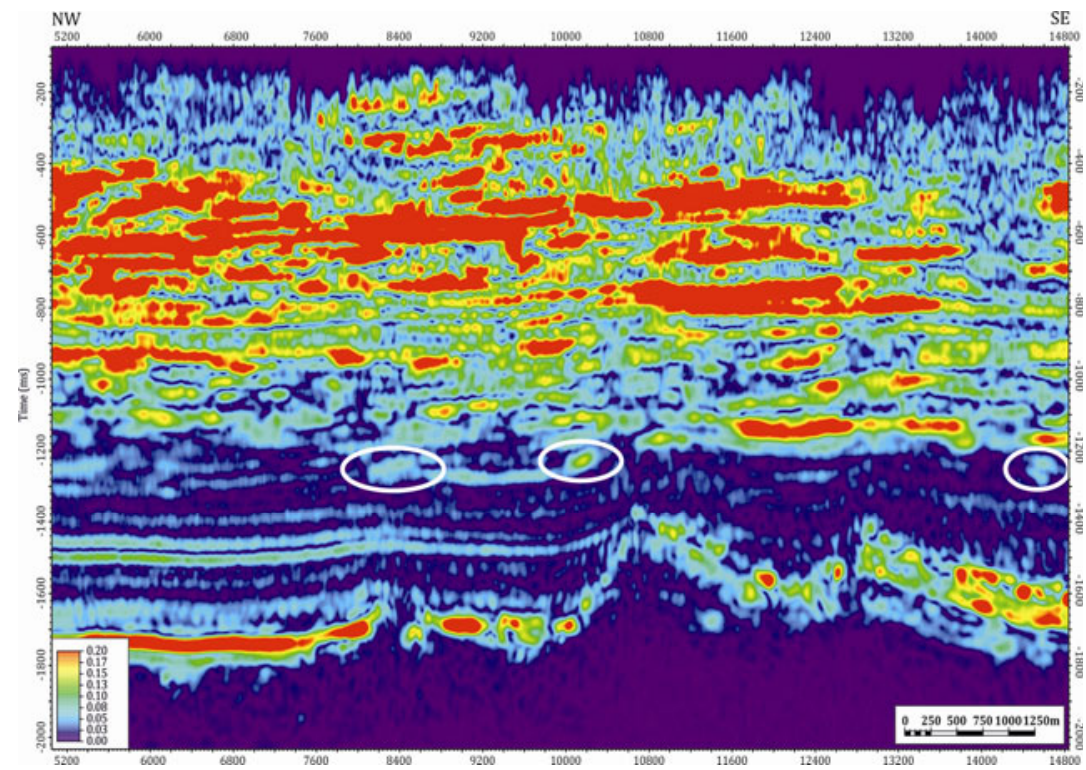

Fig. 10. Seismic profile (crossline 566) after spectra decomposition with the use of FFT algorithm. Frequency slice $-45 \mathrm{~Hz}$, channels are marked with ellipses.

In Fig. 9 the results of instantaneous frequency and peak frequency (the second computed after the CEEMD decomposition) are shown. The colour scale for both figures is identical, and the results are shown for the same horizontal slice. It appears to us that channels are depicted better via the use of instantaneous frequency compared to the peak frequency. Their visibility is clearer and also the linear-like directions are highlighted with a higher accuracy. 


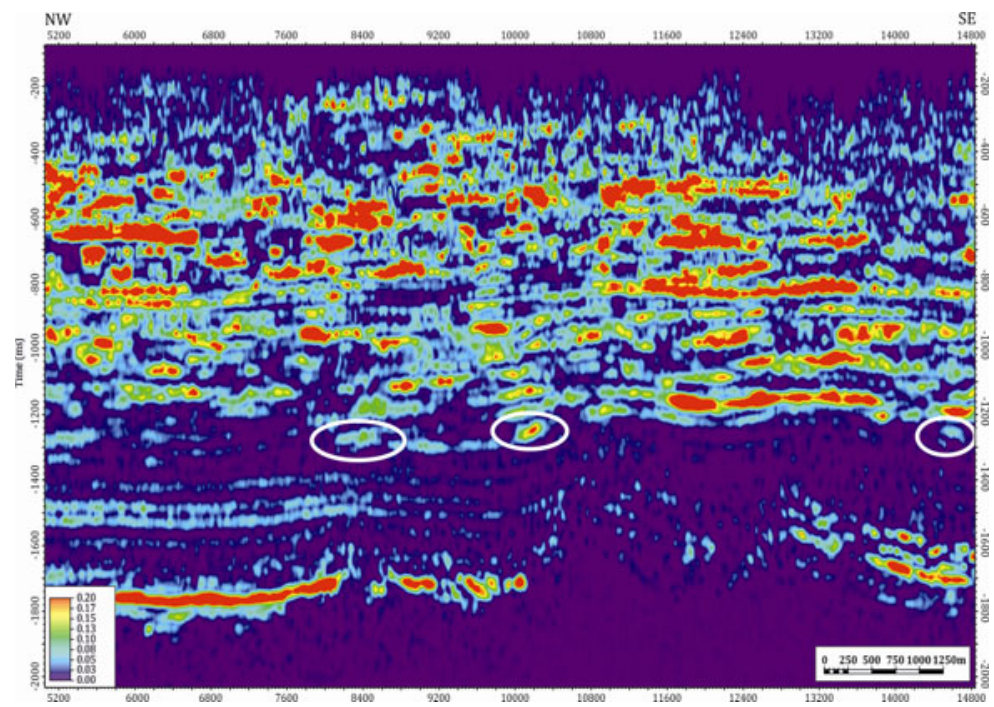

Fig. 11. Seismic profile (crossline 566) after spectral decomposition with the use of CEEMD algorithm. Frequency slice $-45 \mathrm{~Hz}$, percentage of initial Gaussian noise $9 \%, 50$ iterations, channels are marked with ellipses.

Finally, we wanted to compare results of both spectral decomposition algorithms in a seismic profile (Figs. 10 and 11). The seismic profile has the same line as in Fig. 3 and only one frequency slice is presented $-45 \mathrm{~Hz}$. Channels are indicated in the same manner. It is clearly visible that interpretation on the 2D seismic line is significantly more difficult to see than on the seismic horizon. So, as to differences between algorithms it is noticeable that the FFT algorithm has caused a partial loss in time resolution - the window influence caused a typical blur of horizons, while the CEEMD algorithm appears to keep good time resolvability.

\section{DISCUSSION AND CONCLUSION}

During analysis of the presented results the authors have the impression that the FFT manifests with more linear structures, whereas the CEEMD shows more details that are not visible in the FFT (Figs. 4-6). We link this behaviour to the length of the time window used for the FFT decomposition process. The time window used for decomposition process via the use of the FFT algorithm appears to be of a paramount importance. Hence, it is strongly advisable to obtain additional information of the temporal thickness of the seismic data to be interpreted. The length of the window is fixed for the whole computation process and roughly speaking the output is always dependent on this characteristic. Too small features, that are significantly 
smaller than the time window, are not visible after the decomposition process. Information on the temporal range of the interpreted features can be provided by well $\log$ data interpretation and seismic-to-well tie. Once the time window is set basing on well log characteristics and the proper calibration of the specific horizon, a thorough spectral decomposition can be applied. If this requirement is fulfilled, the FFT decomposition can give reasonably accurate results, regardless of the simplicity of the method. Hence we suggest using the FFT method as the primary spectral decomposition algorithm.

The CEEMD algorithm is relatively new, i.e. it is implemented in only a few commercial seismic programmes. Various tests that authors performed during working on the project concluded that it still requires some improvements. Runtimes of this algorithm are extremely time-consuming. For the whole 3D volume it took over 24 hours to complete computation for the CEEMD, whereas the FFT algorithm required approximately just 2 hours. Moreover, different noise levels for the CEEMD resulted in slightly different amplitudes for the given frequencies, which we treat as an imperfection of the method: it appears to alter the spectra of the signal. Further studies will focus on solving these problems and answering questions that have arisen while performing the CEEMD.

Peak frequency that is computed after spectral decomposition was compared with an instantaneous frequency. In our opinion, instantaneous frequency gives better results for our dataset. Again, in this case runtimes benefit an instantaneous frequency ( 24 hours for PF contra on-the-fly computation of IF); nonetheless, we cannot see the benefits of peak frequency. Simultaneously, however, another project is conducted, in which the potential application of peak frequency for thickness estimation is verified, but the authors do not want to mix these two things and prematurely state any conclusions as yet, because the results are still under investigation. Nevertheless, the peak frequency computed after the CEEMD might have some advantages. Future work will be dedicated to applying attributes in different geological settings on different datasets. For the presented results, however, we prefer a more instantaneous frequency.

In conclusion we would like to stipulate that the new algorithm of spectral decomposition (CEEMD) for this particular kind of data does not show significant improvements in comparison with the FFT method. The results are similar, although we value the FFT algorithm more. Its results are more continuous and show better striation that we interpret as channels. The CEEMD results are more influenced by background noise.

We found out that different frequency slices revealed features that we interpret as parts of channels that correspond to slightly different geometries, i.e. features closely related to the geometrical scale of the channel. Higher 
frequencies of spectral decomposition show more detailed features. The application of frequencies as high as $50 \mathrm{~Hz}$ enabled us to depict previously undetected channels that show continuity (Fig. 6A). These smaller features are visible especially clearly for the FFT method and we believe that this algorithm works better for higher frequencies. Additionally, new parameters can be set so that if the scope of interpretation changes the methodology can be easily adjusted.

The display of overlapping different frequencies proved to give good results which are easy to interpret. With the use of such an interpretation we can simultaneously reveal features that are linked to different scales.

Different aspects of applying spectral decomposition are still under examination. During working on the project, many questions arose that still require careful analysis. This paper presents only one aspect of spectral decomposition. Ongoing research is focused on seismic modelling to compare and verify results of the FFT and CEEMD decomposition algorithms. We suggest further reading (see references) for more technical explanation of the methods as well as some case studies that used different algorithms of spectral decomposition. One should always keep in mind that the chosen tools may be valid and give good results for specific geology and the method that gives the best results in one sedimentary basin may not necessarily work in others.

Acknowledgments. The work was part of the study entitled: "Criteria for Recognition of gas-bearing heterolithic Reservoirs in the Miocene Strata of the Forecarpathian Basin Based on Integrated Interpretation of Cores, Well Logs and Seismic Images" (AGH 18.18.140.252, NCN no. NN525 254040) granted to Prof. S.J. Porębski. The authors want to express their deepest gratitude to Prof. K. Pietsch, for her valuable suggestions and support also to Ph.D. P. Marzec, for discussion and comments. The authors are also grateful to CGG, dGB EarthSciences and Schlumberger for providing software within the University Software Donation Scheme. Research was partially supported by grants of the following numbers: 15.11.140.345, 15.11.140.336 and 15.11.140.541. The authors would like to express appreciation to the anonymous reviewer whose constructive comments helped to improve greatly the quality of the paper.

References

Castagna, J.P. (2006), Comparison of spectral decomposition methods, First Break 24, 3, 75-79. 
Chopra, S., and K.J. Marfurt (2007), Seismic attributes for prospect identification and reservoir characterization, SEG Geophysical Developments, Series No. 11, Tulsa, 138-141.

Damuth, J.E., R.O. Kowsmann, R.D. Flood, R.H. Belderson, and M.A. Gorini (1983), Age relationships of distributary channels on Amazon deep-sea fan: Implications for fan growth pattern, Geology 11, 8, 470-473, DOI: 10.1130/0091-7613(1983)11<470: ARODCO $>2.0 . \mathrm{CO} ; 2$.

Han, J., and M. van der Baan (2013), Empirical mode decomposition for seismic time-frequency analysis, Geophysics 78, 2, O9-O19, DOI: 10.1190/GEO2012-0199.1.

Huang, N.E., and Z. Wu (2008), A review on Hilbert-Huang transform: method and its applications to geophysical studies, Rev. Geophys. 46, 2, RG2006, DOI: 10.1029/2007RG000228.

Karnkowski, P.H., and W. Ozimkowski (2001), Structural evolution of the pre-miocene basement in the Carpathian Foredeep (KrakówPrzemyśl region, SE Poland). Prz. Geol. 49, 431-436 (in Polish).

Kotlarczyk, J. (1985), An outline of the stratigraphy of marginal tectonic units of the Carpathian Orogene in the Rzeszów-Przemyśl area. In: J. Kotlarczyk (ed.), Geotraverse Kraków-Baranów-RzeszówPrzemyśl-Komańcza-Dukla, XII Congress of Carpathian-Balkan Geological Association, Cracow, Poland, Guide to excursion 4: 21 32 (in Polish).

Krawiec, D., K. Dzwinel, and S.J. Porębski (2008), Reconstruction of channel systems in lower Sarmatian deposits in SE part of the Carpathian Foreland Basin based on 3D seismic datasets, Międzynarodowa Konferencja Naukowo-Techniczna Geopetrol 2008, Prace Instytutu Nafty i Gazu 150, 279-284 (in Polish).

Li, Y., and X. Zheng (2008), Spectral decomposition using Wigner-Ville distribution with applications to carbonate reservoir characterization, The Leading Edge 27, 8, 1050-1057, DOI: 10.1190/1.2967559.

Masters, T. (1995), Neural, Novel and Hybrid Algorithms for Time Series Prediction, John Wiley \& Sons, Inc. New York.

Oszczypko, N. (1996), The miocene dynamics of the Carpathian Foredeep in Poland, Prz. Geol. 44, 1007-1018 (in Polish).

Oszczypko-Clowes, M., D. Lelek, and N. Oszczypko (2012), Sarmatian paleoecological environment of the Machów Formation based on the quantitative nannofossil analysis - a case study from the Sokołów area (Polish Carpathian Foredeep). Geol. Carpath. 63, 267-294. 
Partyka, G., J. Gridley, and J. Lopez (1999), Interpretational applications of spectral decomposition in reservoir characterization, The Leading Edge 18, 3, 353-360, DOI: 10.1190/1.1438295.

Porębski, S.J., J. Jarzyna, K. Pietsch, M. Bała, J. Dec, T. Danek, H. Sechman, P. Marzec, P. Puskarczyk, M. Warchoł, T. Zorski, K. Cichostępski, M. Kasperska, A. Kwietniak, P. Guzy, and G. Izydor (2014), Criteria for recognition of gas-bearing heterolithic reservoirs in the Miocene Strata of the Forecarpathian Basin based on integrated interpretation of cores, well logs and seismic images, Research program AGH 18.18.140.252, NCN no. N N525 254040, Polish National Science Centre (unpublished report; in Polish).

Taner, M.T., F. Koehler, and R.E. Sheriff (1979), Complex seismic trace analysis, Geophysics 44, 6, 1041-1063, DOI: 10.1190/1.1440994.

Received 16 June 2015

Received in revised form 19 November 2015

Accepted 29 December 2015 